\title{
"PENGARUH KOMPENSASI DAN DISIPLIN KERJA TERHADAP PRODUKTIVITAS KERJA KARYAWAN KONTRAK BUILDING MAINTENANCE AND SERVICES, PADA VICO MUARA BADAK KALTIM"
}

\author{
Dian Irma Aprianti \\ (Fakultas Ekonomi, Universitas Widya Gama Mahakam) \\ Jl. KH. Wahid Hasyim, Sempaja, Samarinda, Kalimantan Timur, Indonesia \\ Telp : (0541) 734294-737222, Fax : (0541) 736572 \\ Email : dianirma@uwgm.ac.id
}

\begin{abstract}
Abstrak
Menciptakan lingkungan kerja yang kondusif tentunya tidak dengan begitu saja dapat diwujudkan oleh perusahaan. Perusahaan harus mampu memberikan motivasi kepada para karyawannya agar karyawan terdorong untuk melaksanakan tugasnya dan dapat meningkatkan produktivitas perusahaan berupa perbaikan infrastruktur sebagai penunjang produktivitas VICO Indonesia secara menyeluruh. Salah satu jalan untuk memotivasi karyawan Building Maintenance and Services agar dapat diberdayakan seefektif dan seefisien mungkin guna meningkatkan produktivitas perusahaan adalah dengan jalan pemberian kompensasi dan penerapan kedisiplinan kerja kepada mereka. Hal ini diharapkan dapat membentuk suatu pola hubungan baik antara para karyawan dan perusahaan dimana para karyawan akan berpikir bahwa perusahaan tempat dimana mereka bekerja bisa memahami serta mengetahui kebutuhan hidup yang menjadi pemicu mengapa mereka bekerja.
\end{abstract}

\section{Kata Kunci : Kompensasi, Disiplin Kerja, Produktivitas}

\section{PENDAHULUAN}

\section{Latar Belakang Masalah}

Perusahaan adalah suatu lembaga yang diorganisir dan dijalankan untuk menyediakan barang dan jasa agar dapat melayani permintaan konsumen akan kebutuhan mereka. Dalam melaksanakan proses produksinya, suatu perusahaan membutuhkan faktor-faktor produksi yang dapat menunjang tercapainya tujuan perusahaan. Faktor-faktor tersebut adalah bahan baku, modal, dan manusia.

Karyawannya dan kedisiplinan kerja merupakan suatu aturan perusahan untuk menambah produktivitas kerja. Oleh karena itu pihak perusahaan harus melakukan suatu penilaian yang teliti mengenai prestasi kerja yang dihasilkan oleh tiap-tiap karyawan tersebut. Hal tersebut dilaksanakan oleh pihak perusahaan karena perusahaan tersebut menghendaki adanya suatu prestasi kerja yang maksimal dari biaya kompensasi yang mereka keluarkan.

Sedangkan apabila dilihat dari sudut pandang karyawan, kompensasi dan kedisiplinan kerja dipandang sebagai alat untuk mempertahankan kelangsungan hidupnya secara ekonomis untuk memenuhi kebutuhan hidupnya karena merupakan suatu kenyataan yang tidak dapat disangkal bahwa motivasi dasar bagi kebanyakan orang menjadi pegawai dalam suatu perusahaan adalah untuk mencari nafkah.

Dalam pemberian kompensasi berupa gaji, upah lembur, tunjangan kesehatan dan tunjangan perumahan diharapkan karyawan bisa melaksanakan pekerjaannya dengan bersamangat karna kebutuhan ekonomi sedikit banyaknya bisa terpenuhi sehingga karyawan dapat mencintai pekerjaan serta menjadi pendorong secara psikologis sebagai sarana untuk meningkatkan disiplin tinggi, adapun

Vol 5, No 2 (2016): Jurnal Ekonomika (Manajemen, Akuntansi, dan Perbankan Syari'ah)-EKONOMI-UWGM 
tingkat kedisiplinannya berupa ketepatan waktu, tanggung jawab terhadap pekerjaan, penggunaan seragam kerja, penggunaan peralatan kerja yang sesuai dengan prosedur dan meningkatkan hubungan harmonis antara karyawan dan pimpinannya sehingga dalam produktivitasnya dapat menyelesaikan Work Order tepat waktu dan memenuhi target yang telah ditentukan oleh Building Maintenance and Services.

Building Maintenance and Services merupakan divisi dari Field Services Departmen yang bergerak di bidang perbaikan infrastruktur untuk menunjang kegiatan operasional VICO Indonesia lapangan Badak dengan jumlah karyawan kontrak 32 orang, untuk melaksanakan produktivitasnya Building Maintenance and Services bekerja berdasarkan Work Order dari Department yang ada di VICO Indonesia yang dibuat melalui Software VICO Indonesia yang di berinama MAXIMO.

Dilihat dari summary data laporan tahunan Work Order status Building Maintenance and Services mengalami penurunan produktivitas kerja dari target minimal 30 WO setiap bulan atau minimal 360 WO setiap tahun yang harus diselesaikan seperti terlihat dalam tabel I.1

Tabel.1 Yearly WO Report

\begin{tabular}{|c|c|c|c|c|c|c|c|c|c|c|c|}
\hline \multirow[b]{2}{*}{ No. } & \multirow{2}{*}{$\begin{array}{l}\text { Work } \\
\text { Order } \\
\text { Status }\end{array}$} & \multicolumn{10}{|c|}{ Year } \\
\hline & & 2011 & $\begin{array}{c}\text { Prog } \\
\%\end{array}$ & 2012 & $\begin{array}{c}\text { Prog } \\
\%\end{array}$ & 2013 & $\begin{array}{c}\text { Prog } \\
\%\end{array}$ & 2014 & $\begin{array}{c}\text { Prog } \\
\%\end{array}$ & 2015 & $\begin{array}{c}\text { Prog } \\
\%\end{array}$ \\
\hline 1 & Selesai & 362 & 87.86 & 367 & 87.5 & 356 & 81.28 & 338 & 81.06 & 335 & 69.36 \\
\hline 2 & $\begin{array}{l}\text { Belum } \\
\text { dikerjaka } \\
\mathrm{n}\end{array}$ & 35 & 8.5 & 45 & 11.03 & 67 & 15.30 & 65 & 15.59 & 67 & 13.87 \\
\hline 3 & $\begin{array}{l}\text { Batal } \\
\text { dikerjaka } \\
\mathrm{n}\end{array}$ & 15 & 3.64 & 6 & 1.47 & 15 & 3.42 & 14 & 3.36 & 81 & 16.77 \\
\hline & otal WO & 412 & & 408 & & 438 & & 417 & & 483 & \\
\hline
\end{tabular}

Berdasarkan uraian mengenai kompensasi, disiplin kerja, dan produktivitas perusahaan diatas, maka penulis tertarik untuk mengadakan penelitian yang kemudian akan dituangkan dalam bentuk tulisan ilmiah engan demikian penulis melakukan penelitian tentang "Pengaruh Kompensasi dan Disiplin kerja Terhadap Produktivitas Kerja Karyawan Kontrak Building Maintenance and Services pada VICO Muara Badak, KALTIM ". dengan perumusan masalah sebagai berikut :

\section{METODOLOGI PENELITIAN}

Populasi dan Sampel Penelitian
1. Apakah Kompensasi dan Disiplin kerja berpengaruh terhadap produktivitas kerja karyawan kontrak pada divisi BUILDING MAINTENANCE AND SERVICES.

2. Dari jenis kompensasi dan kedisiplinan kerja tersebut, manakah yang berpengaruh lebih dominan terhadap produktivitas karyawan kontrak pada divisi BUILDING MAINTENANCE AND SERVICES

Dalam penelitian ini, jumlah populasi keseluruhan karyawan Kontraktor Building Maintenance and Services di Field Services Departmen Vico Indonesia, Muara Badak yang

75 
berjumlah 32 orang karyawan. Kemudian, dikarenakan jumlah populasi yang kecil, maka akan digunakan teknik Sampling Jenuh / sensus dimana seluruh karyawan yang berjumlah 32 orang ini akan penulis jadikan sebagai sampel dalam penelitian.

\section{Tehnik Pengumpulan Data}

Proses pengumpulan data yang diperlukan dalam pembahasan ini melalui dua tahap penelitian, yaitu:

\section{Studi Kepustakaan (Library Research)}

Studi kepustakaan digunakan untuk mengumpulkan data sekunder dari perusahaan, landasan teori dan informasi yang berkaitan dengan penelitian ini dengan cara dokumentasi. Studi dilakukan antara lain dengan mengumpulkan data yang bersumber dari literatur-literatur, bahan kuliah, dan hasil penelitian lainnya yang ada hubungannya dengan objek penelitian. Hal ini dilakukan untuk mendapatkan tambahan pengetahuan mengenai masalah yang sedang dibahas.

2. Studi Lapangan (Field Research)

Dalam penelitian ini penulis mengumpulkan data yang diperlukan dengan cara melakukan pengamatan langsung pada Building Maintenance and Services, baik melalui observasi, penyebaran kuesioner kepada para karyawan, dan wawancara.

Penelitian Lapangan dilakukan dengan cara :

a. Wawancara adalah metode untuk mendapatkan data dengan cara melakukan tanya jawab secara langsung dengan pihak-pihak yang bersangkutan guna mendapatkan data dan keterangan yang menunjang analisis dalam penelitian.

b. Observasi adalah teknik pengumpulan data dengan cara melakukan pengamatan langsung pada obyek yang diteliti sehingga diperoleh gambaran yang jelas mengenai masalah yang dihadapi.

c. Kuesioner, adalah pengumpulan data dengan cara menyebarkan daftar pertanyaan kepada responden yang dijadikan sebagai sampel penelitian.

\section{Metode Analisis}

\section{Analisis Deskriptif Kuantitatif}

Analisis Kuantitatif dalam penelitian ini adalah :

1) Dalam mengetahui hubungan dan pengaruh antara kemanfaatan dan kemudahan penggunaan teknologi informasi dengan kinerja karyawan Building Maintenance and Services digunakan teknik analisis regresi berganda, untuk mengetahui besarnya pengaruh secara kuantitatif dari suatu perubahan (variabel $\mathrm{X}$ ) terhadap kejadian lainnya (variabel Y). Analisis regresi menggunakan rumus persamaan regresi berganda

$\mathrm{Y}=\mathrm{a}+\mathrm{b} 1 \mathrm{X} 1+\mathrm{b} 2 \mathrm{X} 2$

Dimana :

Produktivitas

$\mathrm{Y}=$ Variabel dependen, yaitu $\mathrm{X} 1=$ Variabel independen, yaitu Kompensasi

$\mathrm{X}_{2}=$ Variabel independen, yaitu Disiplin kerja

$\mathrm{a}=$ Konstanta yang merupakan rata-rata nilai $\mathrm{Y}$ pada saat nilai X1, dan X2 sama dengan nol

b1 = koefisien regresi parsial, mengukur rata-rata nilai $\mathrm{Y}$ untuk tiap perubahan $\mathrm{X} 1$ dengan menganggap X2 konstan.

b2 = koefisien regresi parsial, mengukur rata-rata nilai $\mathrm{Y}$ untuk tiap perubahan $\mathrm{X} 2$ 


\section{dengan menganggap X1 konstan.}

2) Analisis Koefisien Determinasi (R2)

Pada model linear berganda ini, akan dilihat besarnya kontribusi untuk variabel bebas secara bersama-sama terhadap variabel terikatnya dengan melihat besarnya koefisien determinasi totalnya (R2). Jika (R2) yang diperoleh mendekati 1 (satu) maka dapat dikatakan semakin kuat model tersebut menerangkan hubungan variabel bebas terhadap variabel terikat. Sebaliknya jika (R2) makin mendekati 0 (nol) maka semakin lemah pengaruh variabelvariabel bebas terhadap variabel terikat.

3) Uji F (Uji Serempak)

Uji ini digunakan untuk mengetahui pengaruh bersama-sama variabel bebas terhadap varibel terikat. Dimana Fhitung > Ftabel, maka H1 diterima atau secara bersama-sama variabel bebas dapat menerangkan variabel terikatnya secara serentak. Sebaliknya apabila Fhitung < Ftabel, maka H0 diterima atau secara bersama-sama variabel bebas tidak memiliki pengaruh terhadap variabel terikat. Untuk mengetahui signifikan atau tidak pengaruh secara bersamasama variabel bebas terhadap variabel terikat maka digunakan probability sebesar 5\% $(\alpha=0,05)$.

Jika sig > $\dot{\alpha}(0,05)$, maka H0 diterima H1 ditolak.

Jika sig $<\dot{\alpha}(0,05)$, maka H0 ditolak H1 diterima.

4) Uji T (Uji Parsial)

Uji ini digunakan untuk mengetahui apakah masing-masing variabel bebasnya secara sendiri-sendiri berpengaruh secara signifikan terhadap variabel terikatnya. Dimana Ttabel > Thitung, H0 diterima. Dan jika Ttabel < Thitung, maka H1 diterima, begitupun jika sig > $\dot{\alpha}(0,05)$, maka $\mathrm{H} 0$ diterima $\mathrm{H} 1$ ditolak dan jika sig $<\dot{\alpha}(0,05)$, maka H0 ditolak H1 diterima.

\section{ANALISIS DAN PEMBAHASAN}

Uji Validitas

Tabel.2 Uji Validitas

\begin{tabular}{c|c|c|c}
\hline Item & $\begin{array}{c}\text { Pearson } \\
\text { Correlation }\end{array}$ & $\mathrm{R}_{\text {Tabel }}$ & Keterangan \\
\hline X1.1 & 0,675 & 0,3550 & Valid \\
X1.2 & 0,650 & 0,3550 & Valid \\
X1.3 & 0,599 & 0,3550 & Valid \\
X1.4 & 0,549 & 0,3550 & Valid \\
X1.5 & 0,411 & 0,3550 & Valid \\
X1.6 & 0,525 & 0,3550 & Valid \\
X1.7 & 0,368 & 0,3550 & Valid \\
X2.1 & 0.469 & 0,3550 & Valid \\
X2.2 & 0.472 & 0,3550 & Valid \\
\hline
\end{tabular}




\begin{tabular}{|c|c|c|c|}
\hline X2.3 & 0.527 & 0,3550 & Valid \\
\hline X2.4 & 0.445 & 0,3550 & Valid \\
\hline X2.5 & 0.580 & 0,3550 & Valid \\
\hline X2.6 & 0.413 & 0,3550 & Valid \\
\hline X2.7 & 0.644 & 0,3550 & Valid \\
\hline X2.8 & 0.562 & 0,3550 & Valid \\
\hline Y1 & 0,390 & 0,3550 & Valid \\
\hline Y2 & 0,694 & 0,3550 & Valid \\
\hline Y3 & 0,596 & 0,3550 & Valid \\
\hline Y4 & 0,530 & 0,3550 & Valid \\
Y5 & 0,463 & 0,3550 & Valid \\
Y6 & 0,542 & 0,3550 & Valid \\
\hline Y7 & 0,421 & 0,3550 & Valid \\
Y8 & 0,596 & 0,3550 & Valid \\
Y9 & 0,500 & 0,3550 & Valid \\
\hline
\end{tabular}

Sumber : data yang diolah

Berdasarkan tabel hasil uji validitas di atas, diketahui bahwa seluruh item pertanyaan yang digunakan dalam penelitian ini adalah valid, yang ditunjukkan dengan nilai dari masing-masing item pertanyaan memiliki nilai Pearson Correlation positif dan lebih besar dari pada nilai $\mathrm{R}_{\text {tabel }}$

\section{Uji Reliabilitas}

Tabel.3 Hasil uji Realibilitas

\begin{tabular}{ccc}
\hline Cronbach's Alpha & $\begin{array}{c}\text { Cronbach's Alpha Based on } \\
\text { Standardized Items }\end{array}$ & N of Items \\
\hline .730 & .872 & 25 \\
\hline
\end{tabular}

Sumber : data yang diolah

Berdasarkan tabel hasil uji reliabilitas dengan menggunakan software SPSS 16, 24 item variabel (pertanyaan) memiliki koefisien alpha 0,730 lebih besar dari 0,60. Berdasarkan ketentuan di atas maka variabel-variabel dalam penelitian ini reliabel.

\section{Analisis Pemberian Kompensasi dan Disiplin Kerja Terhadap Produktivitas Karyawan}


Tabel.4 Analisis Produktivitas

\begin{tabular}{|c|c|c|c|c|c|c|}
\hline \multirow{2}{*}{\multicolumn{2}{|c|}{ Model }} & \multicolumn{2}{|c|}{$\begin{array}{l}\text { Unstandardized } \\
\text { Coefficients }\end{array}$} & \multicolumn{3}{|l|}{$\begin{array}{l}\text { Standardized } \\
\text { Coefficients }\end{array}$} \\
\hline & & B & Std. Error & Beta & $\mathrm{t}$ & Sig. \\
\hline \multirow[t]{3}{*}{1} & (Constant) & .375 & 5.899 & & .063 & .950 \\
\hline & Compensasi & .631 & .210 & .466 & 3.005 & .005 \\
\hline & Disiplin & .524 & .216 & .377 & 2.429 & .022 \\
\hline
\end{tabular}

Sumber : data yang diolah

Dari tabel diatas yang
pengolahan data menggunakan

software SPSS 16.0, dapat diperoleh persamaan regresi linear berganda sebagai berikut:

$\mathbf{Y}=\mathbf{0 , 3 7 5}+\mathbf{0 , 6 3 1} \mathrm{X}_{\mathbf{1}}+\mathbf{0 , 5 2 4 X 2}$

$\mathrm{a}=0,375$; artinya apabila variabel kompensasi $\left(\mathrm{X}_{1}\right)$, dan Disiplin Kerja $=0$, maka nilai dari variabel produktivitas karyawan $(\mathrm{Y})=$ 0,375 .

$\mathrm{b}_{1}=0,631 ;$ artinya apabila kenaikan variabel Disiplin Kerja
(X2) konstan, maka kenaikan variabel kompensasi $\left(\mathrm{X}_{1}\right)$ sebesar 1 satuan akan menyebabkan kenaikan variabel produktivitas karyawan (Y) sebesar 0,631. $\mathrm{b}_{2}=0.524 ;$ artinya apabila kenaikan variabel kompensasi $\left(\mathrm{X}_{1}\right)$ konstan, maka kenaikan variabel disiplin kerja $\left(\mathrm{X}_{2}\right)$ sebesar 1 satuan akan menyebabkan kenaikkan variabel produktivitas karyawan (Y) sebesar 0,524.

\section{Analisis dan Pembahasan Koefisien Determinasi $\left(\mathbf{R}^{2}\right)$}

Tabel.5 Analisis Koefisiensi Determinasi (R2)

\begin{tabular}{|c|c|c|c|c|c|c|c|c|c|}
\hline \multirow[b]{2}{*}{ Model } & \multirow[b]{2}{*}{$\mathrm{R}$} & \multirow[b]{2}{*}{$\begin{array}{c}\mathrm{R} \\
\text { Square }\end{array}$} & \multirow[b]{2}{*}{$\begin{array}{c}\text { Adjusted R } \\
\text { Square }\end{array}$} & \multirow[b]{2}{*}{$\begin{array}{l}\text { Std. Error } \\
\text { of the } \\
\text { Estimate }\end{array}$} & \multicolumn{5}{|c|}{ Change Statistics } \\
\hline & & & & & $\begin{array}{c}\text { R Square } \\
\text { Change }\end{array}$ & $\begin{array}{c}\text { F } \\
\text { Change }\end{array}$ & df1 & df2 & $\begin{array}{l}\text { Sig. F } \\
\text { Change }\end{array}$ \\
\hline 1 & $.761^{\mathrm{a}}$ & .580 & .551 & 2.44331 & .580 & 19.984 & 2 & 29 & .000 \\
\hline
\end{tabular}

Sumber : data yang diolah

Dalam ringkasan hasil regresi yang ditunjukkan pada table diatas dilihat dari nilai Adjusted R-Square yang besarnya 0,551 menunjukkan bahwa proporsi pengaruh variabel kompensasi dan Disiplinkerja terhadap variabel Produktivitas Kerja 
sebesar 55.1\%. Artinya, pemberian kompensasi dan disiplin kerja terhadap Produktivitas Kerja memiliki pengaruh sebesar $55,1 \%$ sedangkan sisanya $\quad 44,9 \%$ $(100 \%$ - 55,1\%) dipengaruhi oleh faktor-faktor lain yang tidak di teliti dalam penelitian ini.

\section{Uji F (Serempak)}

Tabel.6 Uji Serempak

\begin{tabular}{lrrrrrr}
\hline Model & Sum of Squares & df & Mean Square & F & \multicolumn{1}{c}{ Sig. } \\
\hline Regression & 238.595 & 2 & 119.298 & 19.984 & $.000^{\mathrm{a}}$ \\
Residual & 173.123 & 29 & 5.970 & & \\
Total & 411.719 & 31 & & & \\
\hline
\end{tabular}

a. Predictors: (Constant), Disiplinkerja, Compensasi

b. Dependent Variable: Y

\section{Sumber : data yang diolah}

Uji serempak atau uji $\mathrm{F}$ merupakan uji secara bersama-sama untuk menguji signifikansi pengaruh variabel kompensasi dan Disiplin Kerja secara bersama-sama terhadap variabel produktivitas karyawan (Y) dengan menggunakan software SPSS 16. Uji $F$ dilakukan dengan membandingkan $F_{\text {hitung }}$ dengan $F_{\text {tabel. }}$ Berdasarkan ringkasan hasil regresi berganda dari tabel V.12 ditunjukkan bahwa $F_{\text {hitung }}$ sebesar 19,984, sedangkan hasil $\mathrm{F}_{\text {tabel }}$ pada tabel distribusi dengan tingkat kesalahan 5\% adalah sebesar 3,33. Hal ini berarti $F_{\text {hitung }}>F_{\text {tabel }}(19,984>3,33)$.
Perhitungan tersebut menunjukkan bahwa variabel kompensasi $\left(\mathrm{X}_{1}\right)$ dan Disiplin kerja $\left(\mathrm{X}_{2}\right)$ secara bersama-sama mempunyai pengaruh yang positif dan signifikan terhadap variabel produktivitas karyawan (Y). Maka penulis menyimpulkan hipotesis pertama pada penelitian ini yang menyatakan bahwa variabel bebas yang terdiri dari kompensasi $\left(\mathrm{X}_{1}\right)$, dan Disiplin Kerja (X2) secara bersamasama dan simultan berpengaruh positif dan signifikan terhadap produktivitas karyawan (Y) terbukti dan dapat diterima.

\section{Uji T (Parsial)}

Tabel. 7 Uji Uji Parsial

\begin{tabular}{l|ccccc}
\hline & Unstandardized Coefficients & Coefficients & & \\
& C Std. Error & Beta & t & Sig. \\
\hline
\end{tabular}

80 


\begin{tabular}{l|rrrrr}
\hline 1 (Constant) & .375 & 5.899 & & .063 & .950 \\
Compensasi & .631 & .210 & .466 & 3.005 & .005 \\
Disiplin & .524 & .216 & .377 & 2.429 & .022 \\
\hline
\end{tabular}

a. Dependent Variable: Produktivitas

b. Dependent Variable: Y

Sumber : data yang diolah

Pengujian ini untuk melihat sejauh mana pengaruh secara terpisah dari masingmasing variabel bebas (X) terhadap variabel terikat $(\mathrm{Y})$ berdasarkan hasil regresi yang ada pada tabel V.13 uji $\mathrm{t}$ dilakukan dengan membandingkan nilai $t_{\text {hitung dengan }} t_{\text {tabel }}$ dengan tingkat kesalahan 5\% yakni sebesar 2,045. Apabila $t_{\text {hitung }}>t_{\text {tabel }}$ maka dapat disimpulkan variabel tersebut mempunyai pengaruh yang signifikan.

1. Variabel Kompensasi $\left(\mathrm{X}_{1}\right)$

Nilai $t_{\text {hitung }}$ untuk variabel ini sebesar 3,005. Sementara itu nilai pada tabel distribusi 5\% sebesar 2,045. Maka $t_{\text {hitung }}(3,005)>t_{\text {tabel }}$ $(2,045)$. Hal ini berarti variabel kompensasi $\left(\mathrm{X}_{1}\right) \quad$ mempunyai pengaruh yang positif. Hal ini juga diperkuat dengan nilai signifikansi $(0,005<0,050)$ artinya variabel kompensasi $\left(\mathrm{X}_{1}\right)$ berpengaruh positif dan signifikan terhadap produktivitas karyawan.

2. Variabel Disiplin Kerja $\left(\mathrm{X}_{2}\right)$
Nilai $t_{\text {hitung }}$ untuk variabel ini sebesar 2,429 Sementara itu nilai pada tabel distribusi 5\% sebesar 2,045. Maka $t_{\text {hitung }}(2,429)>t_{\text {tabel }}$ (2,045). Hal ini berarti variabel disiplin kerja $\left(\mathrm{X}_{2}\right)$ mempunyai pengaruh yang positif. Hal ini juga diperkuat dengan nilai signifikansi $(0,022<0,050)$ artinya variabel Disiplin kerja $\left(\mathrm{X}_{2}\right)$ berpengaruh positif dan signifikan terhadap produktivitas karyawan.

Berdasarkan hasil uji $\mathrm{t}$ di atas dengan menggunakan software SPSS 16.00, maka dapat disimpulkan bahwa variabel yang paling dominan mempengaruhi produktivitas karyawan adalah variabel kompensasi $\left(\mathrm{X}_{1}\right)$ dengan nilai $\mathrm{t}$ hitung yang paling besar (3,005), dengan signifikansi sebesar 0,005 yang lebih kecil dari nilai tingkat kesalahan 0,050 . Dengan demikian hipotesis kedua pada penelitian yang menyatakan bahwa variabel kompensasi $\left(\mathrm{X}_{1}\right)$ adalah variabel yang paling dominan berpengaruh terhadap kinerja karyawan terbukti dan dapat diterima.

\section{Pembahasan Hasil Penelitian dan Pengujian Hipotesis}

Dari hasil regresi diatas kita dapat melihat beberapa hubungan antara variabel bebas (independent) dan variabel terikat (dependent) :

\section{Pengaruh Variabel Kompensasi} $\left(\mathrm{X}_{1}\right)$ Terhadap Produktivitas Karyawan (Y)

Variabel kompensasi berpengaruh positif dan signifikan terhadap produktivitas karyawan 
dan memiliki tingkat signifikansi tertinggi. Variabel kompensasi ini merupakan variabel yang mendukung peningkatan produktivitas karyawan Building Maintenance and Services di VICO Indonesia lapangan Badak dikarenakan pemberian kompensasi berupa gaji, bonus, THR, Jaminan kesehatan dan lain - lain yang dirasakan oleh para responden atau karyawan lebih mewakili terjadinya peningkatan produktivitas tersebut. Hal ini mengindikasikan asumsi awal penulis terbukti benar yang menganggap bahwasanya saat pemberian kompensasi kepada karyawan dilakukan dengan baik dan benar oleh perusahaan, hal tersebut akan mampu meningkatkan produktivitas para karyawan dengan terpenuhinya kebutuhan mereka dengan pendapatan yang mereka hasilkan.

\section{KESIMPULAN}

Berdasarkan hasil analisis dan pembahasan yang telah dikemukakan pada bab sebelumnya, maka dapat ditarik kesimpulan sebagai berikut :

1. Variabel kompensasi dan disiplin kerja secara simultan mempunyai pengaruh yang positif dan signifikan terhadap produktivitas karyawan. Hal ini telah dibuktikan melalui uji F, dimana hasil uji $\mathrm{F}$ memperlihatkan bahwa $\mathrm{F}_{\text {hitung }}>\mathrm{F}_{\text {tabel }}$ (19.984 > 3.33) yang berarti hipotesis pertama dalam penelitian ini telah terbukti dan dapat diterima.

\section{Pengaruh Variabel Disiplin Kerja $\left(\mathbf{X}_{2}\right)$ terhadap produktivitas Karyawan (Y)}

Variabel disiplin kerja berpengaruh positif dan signifikan terhadap produktivitas karyawan . Variabel disiplin kerja ini juga merupakan variabel yang mendukung peningkatan produktivitas karyawan Building Maintenance and Services di VICO Indonesia lapangan Badak dikarenakan penerapan disiplin kerja berupa disiplin jam kerja, tanggung jawab terhadap pekerjaan, peralatan kerja yang standar untuk jenis pekerjaan dan lain - lain yang dirasakan oleh para responden atau karyawan mewakili terjadinya peningkatan produktivitas tersebut. Hal ini juga mengindikasikan asumsi awal penulis terbukti benar yang menganggap bahwasanya saat pemberian disiplin kerja kepada karyawan dilakukan dengan baik, benar dan adil oleh perusahaan, hal tersebut akan mampu meningkatkan produktivitas para karyawan dengan terpenuhinya lingkungan kerja yang nyaman dan aman serta terjalinnya kerja sama yang sehat kepada semua karyawan.

2. Dari dua variabel bebas yang mempengaruhi produktivitas karyawan, variabel yang dominan adalah kompensasi $\left(\mathrm{X}_{1}\right)$. Yang telah dibuktikan melalui uji t, dimana hasil uji $\mathrm{t}$ variabel kompensasi memperlihatkan nilai $\quad t_{\text {hitung }}>t_{\text {tabel }}$ $(3.005>2.045)$ dan nilai $t_{\text {hitung }}$ dari variabel kompensasi $\left(\mathrm{X}_{1}\right)$ ini lebih besar dibandingkan nilai thitung dari variabel dan disiplin kerja (X2) yaitu 2.429. Kemudian nilai signifikansi variabel kompensasi $\left(\mathrm{X}_{1}\right)$ lebih kecil dibandingkan dengan nilai $\alpha(0.005<0.050)$ yang berarti hipotesis kedua dalam penelitian ini telah terbukti dan dapat diterima. 


\section{DAFTAR PUSTAKA}

Allo,2002, Analisis kompensasi dan pengaruhnya terhadap kinerja petugas P3KB pada Dinas Kehutanan Propinsi Sulawesi Tengah.

Davis, Fundamental Organization Behavior, 2002, Diterjemahkan Agus Dharma, Erlangga, Jakarta .

Desler, Garry, Manajemen Sumber Daya Manausia, 2007, edisi ketiga, jilid 2, PT. Indeks, Jakarta .

Hani Handoko. Manajemen Personalia dan Sumber Daya Manusia, 2001, BPFE UGM, Yogyakarta.

Hasibuan, Malayu, Manajemen Sumber Daya Manusia, 2013, edisi revisi, cetakan ke 13, PT. Bumi Aksara, Jakarta.

Heidjrachman dan Husnan, Suad, Manajemen Personalia, 2002, BPFE, Yogyakarta.

Kusumawarni, Dwi , 2007, Pengaruh

Semangat Dan Disiplin Kerja Terhadap Produktivitas Karyawan Pada Perusahaan Daerah Air Minum (PDAM) Kabupaten Kudus.

Mathis, Manajemen Sumber Daya Manusia, 2006, edisi kedua, Salemba Empat, Jakarta.

Mondy Waeny, Manajemen Sumber Daya Manusia, 2008, edisi keenam, jilid 1, Erlangga, Jakarta.
Nawawi, Hadari, Manajemen Sumber Daya Manusia, 2008, Cetakan ke 8, UGM Universitas Gadja Mada, Yogyakarta.

Pengertian disiplin kerja, difinisi factor yang mempengaruhi, http://www. Langkah.pembelajaran.com, diakses hari senin 18 April 2016.

Polnaya, 2007, Pengaruh kompensasi Finansial dan Non Finansial terhadap kinerja dosen Universitas Kristen Indonesia, Maluku.

Rapang, Yuniarti Tandi, 2005, Pengaruh Kompensasi Terhadap Produktivitas kerja karyawan pada CV. Petra Jaya Lestari, Bandung.

Sirait, Justine.T., Memahami Aspek Pengolahan SDM Dalam Organisasi, 2006, Gramedia Widiasarana Indonesia, Jakarta.

Sugiono, Metode Penelitian Kualitatif dan $R$ \& D, 2009, cetakan ke 6, Alfabeta, Bandung.

Sugiono, statiska untuk penelitian, 2007, cetakan ke 10, Alfabeta, Bandung.

Umar Husein, Metodologi penelitian,aplikasi dalam pemasaran, 2007, edisi revisi, cetakan 5-PT. Gramedia Pustaka, Jakarta.

Yunarsih Tjutju, Manajemen Sumber Daya Manusia, 2009, edisi kedua, Alfabeta, Bandung. 